\title{
Criopreservación de espermatozoides bovinos extraídos de la cola del epidídimo utilizando los métodos convencional y automatizado
}

\author{
Cryopreservation of bovine spermatozoa from the epididymal tail using conventional \\ and automated methods
}

\author{
A Ribeiro-Peres ${ }^{a}$, L Munita-Barbosa ${ }^{b}$, M Yumi-Kanazawa ${ }^{b}$, MI Mello-Martins ${ }^{c}$, F Ferreira de Souza ${ }^{d}$ \\ ${ }^{a}$ Facultad de Ciencias Agrarias y Veterinarias, UNESP, Jaboticabal, Brasil \\ 'bniversidad de Franca, Franca, Brasil. \\ 'Departamento de Ciencias Clínicas, Universidad de Londrina, Londrina, Brasil. \\ ${ }^{\mathrm{d}}$ Facultad de Medicina Veterinaria y Zootecnia, Universidad Estadual Paulista, Botucatu, Brasil
}

\begin{abstract}
SUMMARY
Cryopreservation of sperm is important to preserve the germplasm from animals of genetic value, which can die unexpectedly. This study compares conventional and automated methods of cryopreservation of spermatozoa obtained from the epididymis of bulls post-mortem. Twenty-two epididymides were obtained from a commercial slaughterhouse. Spermatozoa were collected from the tail of the epididymis using the retrograde flow technique. Thus, the samples, which were diluted in $10 \mathrm{ml}$ of extender without glycerol (Botubov ${ }^{\circledast} \mathrm{I}$, Botupharma, Botucatu, SP, Brazil), were evaluated on motility, sperm vigor, structural and functional (swelling hypoosmotic test) membrane integrity, mitochondrial activity, sperm viability and ADN fragmentation. The samples were divided into two aliquots and diluted in extender with glycerol (Botubov ${ }^{\circledR}$ II, Botupharma, Botucatu, SP, Brazil) at a concentration of 50x10 ${ }^{6}$ motile sperm $/ 0.5$ French straws. One sample was frozen by the conventional method (4 hours at $5^{\circ} \mathrm{C}$, in a refrigerator and 20 min in nitrogen vapor) and the other by the automated method (Cryogen ${ }^{\circledR}$ Dualflex, Neovet, Uberaba, MG, Brazil). The parameters were higher in all the tests of fresh sperm samples, with the exception of the swelling hypoosmotic test, which showed no significant difference when the results were compared with sperm frozen by the conventional method. The average motility of fresh spermatozoa was $74 \%$, and conventional and automated averages were 29 and $25 \%$, respectively. Therefore, although cryopreservation techniques reduce sperm quality parameters, the viability of the sperm is maintained, and these methods can be used to preserve sperm.
\end{abstract}

Key words: sperm, frozen-sperm, bull, epididymis.

\section{RESUMEN}

La criopreservación de espermatozoides es importante para la preservación del germoplasma masculino de animales de valor zootécnico que pueden morir inesperadamente. Este estudio compara los métodos de criopreservación convencional y automatizado de espermatozoides colectados de la cola del epidídimo de toros post mortem. Fueron utilizados 22 epidídimos, colectados en una planta faenadora. Los espermatozoides fueron colectados con la técnica de flujo retrogrado utilizando medio diluyente sin crioprotector (Botubov®I, Botupharma. Botucatu, SP, Brasil), fueron analizados en cuanto a la motilidad, vigor, integridad estructural y funcional de la membrana plasmática, viabilidad, actividad mitocondrial e integridad del ADN. Los espermatozoides fueron separados en dos muestras y diluidos en medio con crioprotector (Botubov®II, Botupharma. Botucatu, SP, Brasil), fueron envasados en pajillas francesas, conteniendo 50x106 espermatozoides móviles por pajilla. Las pajillas fueron congeladas por los métodos convencional $\left(4^{\circ} \mathrm{C}\right.$, durante 4 horas, en nevera doméstica y 20 minutos por encima de la superficie liquida conteniendo nitrógeno líquido) y automatizado (Cryogen ${ }$, Neovet, Uberaba, MG, Brasil). Las muestras de espermatozoides frescos presentaron resultados superiores en todos los parámetros realizados comparados con los métodos de congelación convencional y automatizado, con excepción de los parámetros hipoosmóticos, donde las muestras de espermatozoides frescos no tuvieron alteraciones significativas comparadas con las muestras de espermatozoides criopreservados por el método convencional. La motilidad media de espermatozoides frescos fue de $74 \%$, y de 29 y $25 \%$ con los métodos convencional y automatizado respectivamente. Así, aunque las técnicas de criopreservación reducen los parámetros de calidad espermática, se mantiene la viabilidad de los espermatozoides, pudiendo ser utilizada para la preservación espermática.

Palabras clave: espermatozoide, congelación, bovino, epidídimo.

\section{INTRODUCCIÓN}

La criopreservación de semen es una importante biotecnología reproductiva, que busca promover la conser-

Aceptado: 29.08.2013.

* fafesouza@fmvz.unesp.br vación del germoplasma masculino por tiempo indeterminado. Esta biotecnología, cuando se asocia a la inseminación artificial, representa un mecanismo eficiente para la promoción y difusión de material genético de excelente calidad. La criopreservación de semen proporciona una economía para el productor, al reducir los costos de alimentación y transporte de los reproductores, asi como 
los riesgos de transmisión de enfermedades sexualmente transmisibles (Castelo y col 2008).

Cuando un toro muere inesperadamente, su material genético se pierde. Una forma de preservar el germoplasma de estos animales es la colecta de espermatozoides del epidídimo (Martins y col 2007). Este procedimiento post mortem es considerado una importante herramienta en la utilización de espermatozoides de animales en peligro de extinción (Lambrechts y col 1999). Los espermatozoides colectados del epidídimo pueden ser criopreservados o utilizados de inmediato en la fecundación in vitro (Martins y col 2007) o en la inyección intracitoplasmática en los oócitos (James y col 2002).

Castro y col (2009) estudiaron la viabilidad de espermatozoides de toros colectados del epidídimo, refrigerados a $4{ }^{\circ} \mathrm{C}, 24$ horas después del sacrificio y encontraron resultados similares al de semen eyaculado. El promedio de la motilidad y del vigor espermático fue $60,2 \%$ y 3,1 respectivamente. El número promedio de espermatozoides colectados de la cola de los epidídimos fue de $1,7 \times 10^{9}$, siendo el mínimo de $0,26 \times 10^{9}$ y el máximo de 4,2 × $10^{9}$. En cuanto a la morfología se obtuvo un promedio de $68,9 \%$ de espermatozoides normales, siendo el mínimo de 31,5\% y el máximo de $89,3 \%$, donde la mayoría de los defectos fueron gotas citoplasmáticas distales. Aunque no era el objetivo del estudio, los autores congelaron los espermatozoides obtenidos de los 4 epidídimos (2 toros), siendo que en 2 epidídimos los espermatozoides fueron colectados a las 6 horas y los dos restantes, a las 24 horas del sacrificio. En este análisis, los espermatozoides congelados 6 horas después del sacrificio se mantuvieron viables después de la descongelación (motilidad y vigor espermático de 50\% y 3 respectivamente). Sin embargo, para los espermatozoides colectados 24 horas después del sacrificio los resultados fueron inferiores, con una motilidad de $10 \%$ y vigor 1 .

De esta forma la utilización de espermatozoides congelados, provenientes del eyaculado o del epidídimo, es indispensable para un buen programa de inseminación artificial, ya que la manipulación de espermatozoides frescos o congelados otorga una viabilidad corta del material. El objetivo de congelar células espermáticas es la producción de un banco de las mismas, teniendo a disposición un material sin plazo de vencimiento, potencializando la eficiencia de la reproducción animal (Amirat y col 2004). Sin embargo, el proceso de criopreservación resulta en la disminución de la fertilidad cuando se compara con semen fresco (Gonzalez 2004).

Una de las cuestiones importantes relacionadas con la eficiencia de las técnicas de criopreservación es la velocidad de reducción de la temperatura durante el congelamiento. El tipo de curva utilizada durante la congelación tiene influencia directa en el grado de las lesiones celulares, debido a procesos de deshidratación y formación de cristales de hielo intracelulares (Moore y col 2006).

Existen básicamente dos métodos de congelación de semen, el convencional y el automatizado. En el método convencional las pajillas son acomodadas en una gradilla de metal y refrigeradas a $4{ }^{\circ} \mathrm{C}$, durante 4 horas, en una nevera doméstica. Luego de este periodo, la gradilla de metal con las pajillas, es transferida para una caja de poliestireno, conteniendo nitrógeno líquido y acomodadas $6 \mathrm{~cm}$ por encima de la superficie liquida durante $20 \mathrm{mi}-$ nutos. Finalmente, las pajillas son inmersas en nitrógeno líquido y, posteriormente, almacenadas en un termo de nitrógeno. Por el método automatizado, luego del envase, las pajillas son refrigeradas y congeladas utilizando un equipo congelador de semen automático con un protocolo estándar según recomendaciones del fabricante. Luego de la congelación las pajillas son almacenadas en el termo de nitrógeno líquido (Vasconcelos-Filho 2010).

Generalmente, los técnicos de campo utilizan el método convencional de congelación, utilizando materiales simples como la nevera de la propiedad, para realizar la curva de enfriamiento, y la congelación en la caja de poliestireno con nitrógeno líquido. Esta técnica ha demostrado ser viable, aunque la estandarización de las curvas de enfriamiento y congelación son imprecisas, toda vez que dependen de la calidad del material utilizado, como sellamiento de la nevera, tamaño de la caja de poliestireno y el nivel de nitrógeno. De esta manera, se han desarrollado sistemas electrónicos automatizados portátiles, de bajo costo para el control de las curvas de congelación del semen (Gonzalez 2004). La estandarización de la curva de enfriamiento y de congelación parece ser una ventaja sobre la otra técnica, ya que durante la técnica manual esa estandarización es difícil, ya que depende de la calidad del material utilizado y existe el riesgo de una posible falla humana; además, la practicidad de tener todas las etapas controladas por un aparato constituye otra ventaja (Vasconcelos-Filho 2010).

González (2004) no observó diferencia significativa entre las técnicas de congelación de semen convencional y la automatizada para los test de motilidad, vigor e integridad de membrana plasmática acrosomal y mitocondrial. Entre tanto Vasconcelos-Filho (2010) obtuvo mejores resultados después de la crioconservación utilizando la técnica automatizada de congelación para motilidad y vigor.

Considerando la importancia de la criopreservación de espermatozoides para la reproducción y la escasez de trabajos que comparan las técnicas de criopreservación convencional y automatizada de células espermáticas de bovinos se propone evaluar los efectos del método de criopreservación (convencional versus automatizado) sobre la viabilidad de los espermatozoides colectados del epidídimo de toros post mortem.

\section{MATERIAL Y MÉTODOS}

\section{ASPECTOS ÉTICOS}

El estudio fue realizado de acuerdo con los criterios éticos, después de la aprobación del Comité de Ética de la Universidad de Franca en la Utilización de Animales (CEUA), bajo el número 026/10 el 09 de septiembre de 2010. 


\section{MATERIAL BIOLÓGICO}

Se utilizaron 11 pares de epidídimos (22 epidídimos) de toros, colectados en la planta faenadora. Los testículos fueron colectados a través de la sección del cordón espermático, túnica vaginal y túnica albugínea. Después, fueron colocados en bolsas plásticas, almacenados en una caja térmica, manteniéndolos a una temperatura de $37^{\circ} \mathrm{C}$ y trasladados por 10 minutos hasta el Laboratorio de Reproducción Animal.

\section{EXTRACCIÓN DE ESPERMATOZOIDES DEL EPIDÍDIMO}

Las piezas fueron retiradas de la caja térmica, lavadas con solución fisiológica y la cola del epidídimo aislada del testículo y del tejido conectivo adyacente. Luego, la cola del epidídimo fue secada con una gasa estéril y los espermatozoides fueron colectados con la técnica de flujo retrógrado (Garde y col 1994, Martinez-Pastor y col 2006). Esta técnica consiste en pasar un catéter $n^{\circ} 20$ por el ducto deferente, el cual es conectado a una jeringa de $10 \mathrm{~mL}$, conteniendo medio diluyente a base de TRISyema de huevo, sin crioprotector ${ }^{1}$. Luego, se procedió al lavado de la cola del epidídimo, hasta que todo el contenido de la jeringa extravasó la parte final del mismo; finalmente la muestra fue depositada en una placa de Petri sobre una superficie previamente calentada.

\section{ANÁLISIS ESPERMÁTICO}

Después de la colecta, los espermatozoides fueron analizados en cuanto a motilidad, vigor, concentración, integridad del ADN, integridad estructural y funcional de la membrana plasmática (prueba hipoosmótica), viabilidad espermática (coloración con eosina/nigrosina) y actividad mitocondrial.

Para la evaluación de motilidad y vigor, una alícuota espermática fue depositada sobre una lámina previamente calentada, recubierta por un cubreobjetos y observada en un microscopio de contraste de fase ${ }^{2}$, con el objetivo de 100X. La motilidad se caracterizó por la presencia de movimientos rectilíneos y fue dada en porcentaje (0 a $100 \%$ ). El vigor espermático fue caracterizado de acuerdo con la intensidad de los movimientos espermáticos según una puntuación de $0,1,2,3,4$ y 5 .

La concentración espermática fue evaluada luego de la dilución de 1:20 de los espermatozoides en solución formol-salina. Los espermatozoides diluidos fueron colocados en la cámara de Neubauer y las células fueron contadas en un microscopio de contraste de fase ${ }^{2}$, con objetivo de 400X. El valor obtenido fue dado en millones $/ \mathrm{mL}$.

Botubov®, Botupharma. Botucatu, SP, Brasil

2 Bioval, L1000, China
La integridad del ADN fue valorada utilizándose la coloración con acridine orange ${ }^{3}$, según el método de Thuwanut y col (2008). Fueron analizadas 200 células, siendo consideradas con el ADN íntegro (ADN inactivo - cinta doble) las coloreadas en verde fluorescente, en cuanto los espermatozoides con ADN anormal (ADN desnaturalizado) estaban coloreados en un espectro que varió de amarillo-verdoso a rojo. Los resultados fueron presentados en porcentaje de espermatozoides con ADN íntegro.

La integridad estructural de la membrana fue evaluada por la coloración con sondas fluorescentes (diacetato de 6-carboxifluoresceína ${ }^{4}$ y yoduro de propidio ${ }^{5}$ ), la cual fue realizada de acuerdo con la técnica descrita por Harrison y Vickers (1990). Fueron contadas 200 células, de las cuales fueron consideradas con la membrana íntegra, aquellas coloreadas en verde y con la membrana lesionada, las coloreadas en rojo, o rojo y verde. Los resultados fueron presentados en porcentaje de espermatozoides con membrana integra (de color verde).

La integridad funcional de la membrana fue evaluada por el parámetro hipoosmótico según la técnica descrita por Jeyendran y col (1984), utilizando una solución hipoosmótica de 150 mOsmol. Fueron contadas 200 células espermáticas, en varios campos de la lámina, escogidos aleatoriamente, siendo considerados espermatozoides con integridad funcional de la membrana aquellos que presentaron edema, evidenciado por el enrollamiento de la cola. Los resultados fueron presentados en porcentaje de espermatozoides con integridad funcional de la membrana (cola enrollada en el test).

La viabilidad espermática fue evaluada utilizando una solución de eosina/nigrosina preparada según Barth y Oko (1989). Un frotis fue preparado con una alícuota de $5 \mu \mathrm{L}$ de la solución y la misma cantidad espermática. Después de secar al aire, la lámina fue analizada, contándose 200 células en microscopio óptico ${ }^{2}$ (400X), se consideraron células con la membrana lesionada aquellas coloreadas en rosa. Los resultados fueron presentados en porcentaje de espermatozoides viables (espermatozoides no coloreados de rosa).

La actividad mitocondrial fue evaluada por el método descrito por Hrudka (1987) y Cavalcante y col (2005). Las láminas fueron evaluadas en microscopio de contraste de fase ${ }^{2,}$ con objetivo de $1000 X$. Fueron contadas 200 células, las cuales fueron clasificadas en cuatro categorías, siendo categoría 1- la mayoría de las mitocondrias estaban activas, en las cuales la envoltura mitocondrial tenia apariencia de un cilindro compacto y prominente; categoría 2- envoltura mitocondrial fragmentada, conteniendo

Acridine Orange Base, ref. 235474, Sigma-Aldrich ${ }^{\circledR}$, Munich, Germany

4 6-Carboxyfluorescein diacetate, ref. C5041, Sigma-Aldrich ${ }^{\circledR}, \mathrm{Mu}-$ nich, Germany

5 Propidium iodide, ref. P4170, Sigma-Aldrich $®$, Munich, Germany 
segmentos activos e inactivos con predominancia de los activos; categoría 3- menos de la mitad de la envoltura mitocondrial estaba activa, con pocas mitocondrias activas dispersas; categorías 4- envoltura completamente inactiva. El índice de actividad mitocondrial fue encontrado luego de la multiplicación del número de espermatozoides en cada categoría, por su factor de corrección, siendo la categoría 1, multiplicada por el factor de corrección 1,0; categoría 2, factor de corrección 0,5; categoría 3: factor de corrección 0,25 y categoría 4: factor de corrección 0.

\section{CONGELACIÓN Y DESCONGELACIÓN ESPERMÁTICA}

Después del análisis, el contenido espermático fue separado en dos muestras, que fueron destinadas a congelación por el método convencional y el automatizado. A partir de la concentración espermática de la muestra colectada, la cantidad de diluyente fue calculada en $\mathrm{ml}$. El contenido espermático fue diluido en un medio que contenía aproximadamente $4 \%$ de glicerol ${ }^{6}$ en la solución final. Después de la dilución, las muestras fueron envasadas, a temperatura ambiente de $25^{\circ} \mathrm{C}$, en pajillas francesas de 0,5

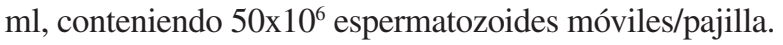

Las pajillas fueron congeladas por los métodos convencional y automatizado. En el método convencional las pajillas fueron acomodadas en una canastilla de metal y refrigeradas a $4^{\circ} \mathrm{C}$, durante 4 horas, en nevera doméstica. Luego de este periodo, la canastilla de metal, con las pajillas, fueron transferidas para una caja de poliestireno, conteniendo nitrógeno líquido y acomodadas $6 \mathrm{~cm}$ por encima de la superficie liquida, durante 20 minutos. Finalmente, las pajillas fueron inmersas en nitrógeno líquido y, posteriormente, almacenadas en un termo de nitrógeno líquido.

Por el método automatizado, luego del envase, las pajillas fueron refrigeradas utilizando un equipo congelador de semen automático ${ }^{7}$ y protocolo estándar para semen bovino, según recomendaciones del fabricante. El protocolo de este método utiliza la tasa de refrigeración lenta de $-0,25{ }^{\circ} \mathrm{C} /$ minuto, temperatura de equilibrio de $5{ }^{\circ} \mathrm{C}$, tiempo de equilibrio de 180 minutos, tasa de congelación lenta de $-5^{\circ} \mathrm{C} /$ minuto y temperatura final de congelación de $-100{ }^{\circ} \mathrm{C}$. Luego de la congelación las pajillas fueron almacenadas en el termo de nitrógeno líquido.

Las pajillas de ambos grupos fueron descongeladas a $37{ }^{\circ} \mathrm{C}$ en baño María, durante 30 segundos, para evaluación de células pos-congelación.

\section{ANÁLISIS ESTADÍSTICO}

Para la descripción de los datos fueron utilizados el promedio y la desviación estándar de cada grupo estudiado. Todos los datos fueron evaluados para la normalidad

Botubov®,Botupharma, Botucatu, SP, Brasil

Cryogen ${ }$, Neovet, Uberaba, MG, Brasil por el test de Shapiro-Wilk. Las variables que no pasaron en el test de normalidad (datos no paramétricos) fueron evaluados por el test de ANOVA on Ranks. Las variables que pasaron el test de normalidad (datos paramétricos) fueron evaluadas por el test One Way ANOVA. Se verificó la correlación por el método de Pearson, entre la motilidad espermática y el índice de actividad mitocondrial en las muestra de espermatozoides frescos y congelados por el método tradicional y automatizado. Se utilizó el Software SigmaStat for Windows Versión 11.0. Los datos obtenidos de cada toro y entre los toros fueron comparados, antes e después de la congelación espermática. El nivel de significancia fue considerado $\mathrm{P}<0,05$.

\section{RESULTADOS}

Las muestras de espermatozoides frescos presentaron resultados superiores $(\mathrm{P}<0,05)$ en los parámetros evaluados de motilidad, vigor, integridad del ADN, integridad estructural de la membrana plasmática (fluorescencia), viabilidad espermática (coloración con eosina/ nigrosina) y actividad mitocondrial cuando comparados a los métodos de congelación convencional y automatizado. Para el parámetro de integridad estructural de la membrana plasmática (hiposmotica) las muestras de espermatozoides frescos no tuvieron alteraciones significativas cuando comparadas con muestras de espermatozoides congeladas por el método convencional. Por otro lado, las muestras de espermatozoides frescos tuvieron alteraciones significativas al compararlas con el método automatizado. En todos los parámetros realizados, las muestras de espermatozoides congelados por el método convencional y automatizado no presentaron diferencias significativas cuando comparadas entre sí (Tabla 1).

Fue verificada una correlación positiva $(r=0,65$ $\mathrm{P}=0,03$ ) entre el índice de actividad mitocondrial y la motilidad espermática después del descongelamiento solo en las muestras sometidas al método de congelación tradicional. No fue observada ninguna correlación para los mismos parámetros en las muestras de espermatozoides frescos o congelados por el método automatizado.

\section{DISCUSIÓN}

La cola del epidídimo es uno de los principales lugares de almacenamiento de los espermatozoides antes de la eyaculación, permitiendo que estas células permanezcan viables y móviles por varias semanas (Reyes-Moreno y col 2002). La cola del epidídimo es capaz de acumular un número suficiente de espermatozoides para varias eyaculaciones (Sostaric y col 2008), lo que torna a este lugar una fuente de germoplasma, aun poco explorada comercialmente en el toro.

En bovinos, existen pocos estudios sobre la colecta, criopreservación y/o inseminación artificial utilizando espermatozoides de la cola del epidídimo (Barker 1954, 
Tabla 1. Parámetros de calidad espermática (media \pm SD) en muestras colectadas del epidídimo de 11 toros antes y después de la congelación por los métodos convencional y automatizado.

Sperm quality parameters (mean $\pm \mathrm{SD}$ ) in samples collected from epididymides of 11 bulls before and after freezing by conventional and automated methods.

\begin{tabular}{|c|c|c|c|}
\hline Parámetro & Espermatozoides frescos & $\begin{array}{l}\text { Congelación } \\
\text { convencional }\end{array}$ & $\begin{array}{l}\text { Congelación } \\
\text { automatizada }\end{array}$ \\
\hline Motilidad (\%) & $74,5 \pm 5,2^{\mathrm{a}}$ & $29,5 \pm 14,9^{b}$ & $25,5 \pm 12,1^{\mathrm{b}}$ \\
\hline Vigor (0 a 5) & $3,5 \pm 0,5^{\mathrm{a}}$ & $2,1 \pm 0,8^{b}$ & $2,0 \pm 0,6^{b}$ \\
\hline Concentración total $\left(\mathrm{x} 10^{9}\right)$ & $2,1 \pm 1,7$ & $--*$ & $--*$ \\
\hline Integridad del DNA (\%) & $99,2 \pm 0,9^{\mathrm{a}}$ & $93,1 \pm 6,1^{\mathrm{b}}$ & $92,4 \pm 13,1^{b}$ \\
\hline Integridad estructural de la membrana (\%) & $77,7 \pm 10,7^{\mathrm{a}}$ & $63,1 \pm 13,6^{b}$ & $69,2 \pm 16,4^{\mathrm{b}}$ \\
\hline Integridad funcional de la membrana $(\%)$ & $69,7 \pm 9,2^{\mathrm{a}}$ & $60,2 \pm 10,0^{\mathrm{ab}}$ & $59,6 \pm 11,4^{\mathrm{b}}$ \\
\hline Viabilidad espermática (\%) & $69,4 \pm 10,7^{a}$ & $53,9 \pm 11,8^{b}$ & $52,7 \pm 9,0^{\mathrm{b}}$ \\
\hline \multicolumn{4}{|l|}{ Actividad mitocondrial } \\
\hline Categoría 1 & $97,6 \pm 36,9^{a}$ & $24,7 \pm 23,7^{b}$ & $32,7 \pm 32,1^{b}$ \\
\hline Categoría 2 & $60,5 \pm 32,6^{\mathrm{a}}$ & $139,6 \pm 21,5^{\mathrm{b}}$ & $117,8 \pm 24,9^{\mathrm{c}}$ \\
\hline Categoría 3 & $24,9 \pm 16,5^{\mathrm{a}}$ & $30,2 \pm 19,0^{\mathrm{a}}$ & $44,7 \pm 19,7^{\mathrm{b}}$ \\
\hline Categoría 4 & $16,9 \pm 9,4^{\mathrm{a}}$ & $5,5 \pm 6,5^{\mathrm{b}}$ & $4,7 \pm 7,1^{b}$ \\
\hline Índice actividad mitocondrial & $67,1 \pm 9,3^{\mathrm{a}}$ & $51,0 \pm 7,9^{b}$ & $51,4 \pm 10,5^{\mathrm{b}}$ \\
\hline
\end{tabular}

Valores con diferente superíndice dentro de la misma fila difieren estadísticamente $(\mathrm{P}<0,05)$.

*Después del análisis, los espermatozoides frescos fueron envasados en pajillas con una concentración estándar de 50x10 espermatozoides móviles por pajilla y congelados posteriormente.

Igboeli y Foote 1968, Martins y col 2007, Castro y col 2009, Martins y col 2009, Barbosa y col 2011), teniendo en cuenta que en algunas situaciones, esta puede ser la última oportunidad para la preservación de los gametos de un toro. Sin embargo, este es el primer estudio que describió a viabilidad de las células espermáticas colectadas del epidídimo y congeladas con un sistema automatizado.

Utilizando la técnica de flujo retrogrado fueron colectados, en promedio 2,1 x $10^{9}$ espermatozoides/animal, lo que corresponde a la cantidad de células obtenidas en una eyaculación (Gonçalves y col 2008). Considerando que el epidídimo es capaz de almacenar varias eyaculaciones, la cantidad colectada podría ser superior, sin embargo los toros utilizados fueron provenientes de una planta faenadora, donde la calidad reproductiva no es un índice considerado. Se optó por utilizar el promedio/animal, ya que de acuerdo con Goovaerts y col (2006) un epidídimo no puede ser control del otro, puesto que hay diferencias significativas en la cantidad y calidad de las células colectadas de los epidídimos del mismo animal.

Las muestras de espermatozoides frescos presentaron resultados superiores en todos los parámetros realizados cuando comparados a los métodos de congelación convencional y automatizado, con excepción del parámetro hiposmótico. En el parámetro hiposmótico las muestras de espermatozoides obtenidas de epidídimo, congeladas por el método convencional, se comportaron de forma similar a las muestras de espermatozoides frescos. Sin embargo, en la tabla 1 se observa que el valor mayor para el parámetro de integridad funcional de membrana fue obtenido para los espermatozoides frescos, un valor intermedio para espermatozoides congelados por el método convencional y un valor menor para los espermatozoides congelados por el método automático. Para los demás parámetros realizados, las muestras de espermatozoides congelados por el método convencional y automatizado no presentaron diferencias significativas cuando comparadas entre sí. Resultados contrarios fueron observados por Terraciano y col (2008), los cuales observaron mejores resultados en el método de congelación automatizado en equinos, especialmente en los parámetros de integridad funcional y estructural de membrana. Gonzáles (2004) también evaluó los métodos de congelación de semen bovino y no observó diferencias significativas entre los métodos convencional y automatizado para las pruebas de motilidad, vigor e integridad de membrana plasmática acrosomal y mitocondrial. Sin embargo, fueron utilizadas muestras de semen de eyaculado y no espermatozoides colectados de la cola del epidídimo, siendo así nuestro experimento el primero en evaluar los dos métodos de congelación utilizando espermatozoides bovinos colectados de la cola del epidídimo. Estos autores utilizaron una curva de refrigeración semejante a la utilizada en el presente estudio $\left(-0,25^{\circ} \mathrm{C} /\right.$ minuto $)$, sin embargo con una tasa 
de congelación más rápida de $-15,5^{\circ} \mathrm{C} /$ minuto. A pesar de las diferencias del origen de las células espermáticas entre los dos estudios (epidídimo y eyaculación) y de las diferencias en la curva de refrigeración y congelación, la motilidad pos-descongelación en los métodos convencional y automatizado fueron semejantes (aproximadamente $30 \%$ ) cuando los autores utilizaron el crioprotector glicerol, siendo el mismo utilizado en el presente estudio.

Algunos parámetros espermáticos evaluados en este estudio, para los espermatozoides de epidídimo pueden predecir la fertilidad, como fue descrito por Correa y col (1997), que relatan una correlación de fertilidad in vivo con la motilidad espermática, resultados del parámetro hiposmótico y morfología. Estos parámetros explican 12 a $18 \%$ de variación cuando evaluados separadamente y $48 \%$ cuando evaluados colectivamente (Brito y col 2003).

En el presente estudio la motilidad de los espermatozoides frescos colectados del epidídimo fue elevada, variando entre 70 a $80 \%$ lo que puede ser considerado dentro de los límites normales para la especie (CBRA 1998). La motilidad espermática es fundamental para que los espermatozoides alcancen el ambiente uterino y el sitio de la fertilización, considerándose el criterio más importante en la evaluación de las células espermáticas antes y después a la criopreservación (Siqueira y col 2007). Martins y col (2007) observaron en su experimento que la motilidad de los espermatozoides colectados del epidídimo $(n=3)$ no sufrieron alteraciones significativas en uno de los toros después de la criopreservación, diferente de los resultados del presente estudio, que independientemente del método de congelación, ocurrió una caída significativa de la motilidad espermática.

Valores inferiores a los observados en los espermatozoides frescos, entre 10 a $45 \%$ de motilidad, fueron encontrados después de la congelación, tanto por el método convencional, así como por el automatizado, lo que está de acuerdo con los resultados de González (2004) en bovinos y Rodello y col (2005) en ovinos que no observaron diferencia significativa entre las técnicas de congelación.

La colecta de los espermatozoides del epidídimo puede ser la última oportunidad para garantizar la preservación del material genético luego de lesión o muerte del reproductor. Algunos estudios han demostrado que estos espermatozoides pueden ser usados en la inseminación artificial in vitro e inyección intra-citoplasmática de espermatozoides con resultados satisfactorios (Barker 1954, James y col 2002, Martins y col 2007). En el presente estudio la motilidad de los espermatozoides, luego de ser congelados, podría ser considerada para su uso en inseminación (Severo 2009), siendo mayor o igual a 30 en $55 \%$ de los toros. Además, fue observado que la cantidad de espermatozoides obtenidos de la cola del epidídimo resultaría en una producción media de 104 dosis por toro, con una variación de 29 a 320, considerando la dosis de insemi-

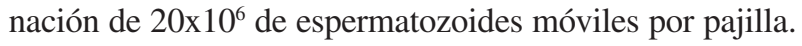
Es importante resaltar que los testículos fueron obtenidos de una planta faenadora comercial, de animales sin valor reproductivo, demostrando así la viabilidad de la técnica en la utilización de toros con fertilidad comprobada que puedan morir inesperadamente. Resultados semejantes fueron obtenidos por Castro y col (2009) que estudiaron la viabilidad de espermatozoides colectados del epidídimo refrigerado de 15 toros y calcularon que podrían ser congeladas un total de 114 dosis/toro, considerando en este caso $30 \times 10^{6}$ espermatozoides móviles por pajilla.

Aunque una evaluación de la fragmentación de ADN pueda parecer poco importante, puede haber una relación entre la integridad del ADN y otras funciones espermáticas, como la motilidad espermática, ya que apenas una pequeña fracción de las proteínas mitocondriales son codificadas por el ADN mitocondrial, siendo que la mayoría de los genes para estas proteínas están localizados en el núcleo. De esta forma, las alteraciones en el núcleo son reflejadas en la función mitocondrial y en el rendimiento celular (Bereiter-Hahn y Jendrach 2010), lo que hace necesario una evaluación completa de la célula espermática. El desarrollo embrionario inicial depende de la integridad del ADN espermático (Rodrigues-Martinez 2005), siendo que la evaluación de la estabilidad del material genético de los espermatozoides pueden proporcionar informaciones adicionales sobre la calidad de las muestras seminales. El análisis estructural de la cromatina espermática es realizado para verificar la susceptibilidad del ADN a la desnaturalización (Freitas-Dell'aqua y col 2009). La integridad del ADN fue inferior en las muestras de espermatozoides congelados, independientemente de la técnica de congelación, lo que comprueba los efectos negativos encontrados por Baumber y col (2003) en equinos. Con esto, los valores de la integridad del ADN, en el presente estudio, se encuentra dentro del rango considerado normal en los bovinos para el semen eyaculado, que está en torno de 2 a 5\% de fragmentación (Garner y col 1994).

La integridad de la membrana de las células espermáticas es un requisito fundamental en el proceso de fertilización. Luego de la congelación, los espermatozoides obtenidos del epidídimo de toros, independiente del método de congelación, sufrieron lesiones en la membrana espermática, comprobadas por el test de fluorescencia con la carboxifluoresceína y yoduro de propidio. A pesar de esto, la congelación por el método convencional fue ligeramente superior en el parámetro hipoosmótico, comparado al método automatizado. La reducción de la fertilidad del espermatozoide luego de la criopreservación es atribuida en gran parte a la alteración de la función y de la estructura de su membrana (Parks y Graham 1992, Medeiros y col 2002). A pesar de esto, tales alteraciones no son exclusivas de los espermatozoides del epidídimo y pueden ser observadas en la misma intensidad del semen eyaculado (Correa y Zavos 1994).

Los resultados del presente estudio indicaron que no hubo interferencia del método de criopreservación sobre la viabilidad espermática, manteniendo más del $60 \%$ de 
células viables. A pesar de esto, los resultados de viabilidad fueron el doble de la mortalidad espermática, lo que indica que los espermatozoides del epidídimo, después del descongelamiento, se comportan de la misma manera que los eyaculados (Celeghini y col 2008), en el cual los espermatozoides inmóviles aun pueden ser viables.

La reducción de la motilidad espermática puede estar asociada a la lesión mitocondrial, pues es necesaria energía tanto para la motilidad como para la fertilización. La mitocondria es la principal fuente de energía para el espermatozoide por su producción de ATP, localizándose en torno de la pieza intermediaria para ofrecer energía y facilitar los movimientos propulsivos del espermatozoide (Connell y col 2002), lo que debería estar relacionado a la motilidad espermática.

A pesar de eso, Barbosa y Esper (1997) y Barbosa y col (2011) no constataron correlación entre motilidad y actividad citoquímica mitocondrial en el semen eyaculado y en los espermatozoides del epidídimo, respectivamente. Por el contrario, Gloria y col (2011) determinaron una correlación positiva entre la actividad mitocondrial y la motilidad total y progresiva del semen eyaculado, sin embargo, ninguna correlación fue verificada en los espermatozoides colectados del epidídimo. En este estudio, la categoría 1 predominó en las muestras de espermatozoides frescos, con modificación para categoría 2 luego de la criopreservación; estos hallazgos concuerdan con los de Cavalcante y col (2005) en caprinos, así como el índice de actividad mitocondrial, que aunque disminuyó, se mantuvo encima de 50. Tal resultado indica una disminución de los niveles de ATP después de la descongelación, la cual se correlaciona con el número de espermatozoides móviles y a la viabilidad espermática (Lindemann y Kanous 1989, Tesarik y col 1993, Januskauskas y Zilinskas 2002). Además, no fueron observadas diferencias significativas para la actividad mitocondrial entre los métodos convencional y automatizado de congelación de espermatozoides, lo que está de acuerdo con los resultados de González (2004) que encontró resultados semejantes en la evaluación de las células espermáticas obtenidas por eyaculación.

A pesar de no haber sido probada la fertilidad in vivo, la posibilidad de utilizar los espermatozoides de epidídimo es real y promisoria, ya que Barker (1954) encontró $63 \%$ de fertilidad luego de realizar una inseminación artificial con espermatozoides congelados obtenidos del epidídimo de toros. Amann y Griel Jr (1974) encontraron una tasa de fertilización similar entre las muestras obtenidas de la cola del epidídimo y de la eyaculación (84\% contra $94 \%$ respectivamente).

Basado en los resultados, se concluyó que aunque las técnicas de criopreservación, convencional y automática, de espermatozoides obtenidos de la cola del epidídimo reducen significativamente todos los parámetros de calidad espermática evaluados, logran mantener la viabilidad de las células espermáticas, pudiendo ser utilizadas con gran potencial para la preservación de las células espermáticas obtenidas del epidídimo en programas de reproducción asistida. Además, la criopreservación automatizada puede sustituir a la convencional sin producir daños a las células espermáticas obtenidas del epidídimo, aunque se deba considerar el mayor costo de los equipos y consumo de nitrógeno líquido cuando esta técnica es utilizada.

\section{REFERENCIAS}

Amann RP, LC Griel Jr. 1974. Fertility of bovine spermatozoa from rete testis, cauda epididymidis, and ejaculated sperm. J Dairy Sci 57, 212-219.

Amirat L, D Tainturier, LT Jeanneau, C Thotin, O Gérard, JL Courtens, M Anton. 2004. Bull semen in vitro fertility after cryopreservation using egg yok LDL: a comparison with Optidyl® a commercial egg yolk extender. Theriogenology 61, 895-907.

Barbosa RT, CR Esper. 1997. Avaliação e demonstração da atividade citocromo $\mathrm{C}$ oxidase em espermatozoides bovinos. Ars Vet 13, 218-223.

Barbosa LM, MY Kanazawa, A Peres, FF Souza. 2011. Viabilidade do sêmen congelado obtido do epidídimo de touros post-mortem. Rev Bras Ci Vet 19, 190-194.

Barker CAV. 1954. Low temperature preservation of bovine epididymal spermatozoa. Can J Comp Med 13, 390-393.

Barth AD, RJ Oko. 1989. Abnormal morphology of bovine spermatozoa. Iowa State University Press, Ames, USA.

Baumber J, BA Ball, JJ Linfor, SA Meyers. 2003. Reactive oxygen species and cryopreservation promote DNA fragmentation in equine spermatozoa. J Androl 24, 621-628.

Bereiter-Hahn J, M Jendrach. 2010. Mitochondrial dynamics. Intern Rev Cell Mol Biol 284, 1-65.

Brito LFC, AD Barth, S Bilodeau-Goeseels, PL Panich, JP Kastelic. 2003. Comparison of methods to evaluate the plasmalemma of bovine sperm and their relationship with in vitro fertilization rate. Theriogenology 60, 1539-1551.

Castelo TS, TR Frota, AR Silva. 2008. Considerações sobre a criopreservação do sêmen de caprinos. Acta Vet Bras 2, 67-75.

Castro JB, VF Casas, FF Souza. 2009. Viabilidade dos espermatozóides colhidos do epidídimo de touros 24 horas post-mortem. Resúmenes del Congresso Brasileiro de Reprodução Animal, Belo Horizonte, Brasil, Pp 379.

Cavalcante TV, CR Esper, JL Ferreira, FEF Dias, HC Azevedo, MF Cordeiro, JAT Souza. 2005. Avaliação da atividade mitocondrial em espermatozóides pós-colheita e pós-descongelação de caprinos das raças Boer e Alpina no outono e primavera. Arch Vet Sc 10, 89-93.

CBRA. 1998. Manual prático para exame andrológico e avaliação de sêmen animal. Editora do Colégio Brasileiro de Reprodução Animal, Belo Horizonte, Brasil, Pp 2-49.

Celeghini ECC, RP Arruda, AFC Andrade, J Nascimento, CF Raphaela, PHM Rodrigues. 2008. Effects that bovine sperm cryopreservation using two different extenders has on sperm membranes and chromatin. Anim Reprod Sc 104, 119-131.

Connell MO, N Mcclure, SEM Lewis. 2002. The effects of cryopreservation on sperm morphology, motility and mitochondrial function. Hum Reprod 17, 704-709.

Correa JR, PM Zavos. 1994. The hypoosmotic swelling test: Its 
employment as an assay to evaluate the functional integrity of the frozen-thawed bovine sperm membrane. Theriogenology 42, 351-360.

Correa JR, MM Pace, PM Zavos. 1997. Relationships among frozen-thawed sperm characteristics accessed via the routine semen analysis, sperm functional tests and fertility of bulls in an artificial insemination program. Theriogenology 48, 721-731.

Freitas-Dell’aqua CPF, AM Crespilho, FO Papa, JA Della'aqua Jr. 2009. Metodologia de avaliação laboratorial do sêmen congelado bovino. Rev Bras Reprod Anim 33, 213-222.

Garde J, M Aguado, S Pérez, D Garrido, M Pérez-Guzmán, V Montoro. 1994. Physiological characteristics of epididymal spermatozoa from post-mortem rams. Theriogenology 41, 203.

Garner DL, LA Johnson, ST Yue, BL Roth, RP Haungland. 1994. Dual DNA staining assessment of bovine sperm viability using SYBR-14 and propidium iodide. J Androl 15, 620-629.

Gloria A, A Contri, I de Amicis, D Robbe, A Carluccio. 2011. Differences between epididymal and ejaculated sperm characteristics in donkey. Anim Reprod Sci 128, 117-122.

Gonçalves PBD, JR Figueiredo, VJ Freitas. 2008. Biotécnicas aplicadas à reprodução animal. $2^{\text {nd }} \mathrm{ed}$. Editora Roca, São Paulo, Brasil.

Gonzalez RA. 2004. Efeito da criopreservação usando diferentes técnicas de congelação e crioprotetores sobre parâmetros espermáticos e a integridade de membrana dos espermatozoides bovino. Tesis doctoral, Faculdade de Medicina Veterinária e Zootecnia, Universidade de São Paulo, Pirassununga, Brasil.

Goovaerts IGF, GG Hoflack, A Van Soom, J Dewulf, M Nichi, A de Kruif, PEJ Bols. 2006. Evaluation of epididymal semen quality using the Hamilton-Thorne analyser indicates variation between the two caudae epididymides of the same bull. Theriogenology 66, 323-330.

Harrison RAP, SE Vickers. 1990. Use of fluorescent probes to assess membrane integrity in mammalian spermatozoa. $J$ Reprod Fert 88, 343-352.

Hrudka F. 1987. Cytochemical and ultracytochemical demonstratation of cytochrome c oxidase in spermatozoa and dynamics of its changes accompanying ageing or induced by stress. Int J Androl 19, 809-828.

Igboeli G, RH Foote. 1968. Maturation changes in bull epididymal spermatozoa. J Dairy Sci 51, 1703-1705.

James AN, H Green, S Hoffman, AM Landry, D Paccamonti, RA Godke. 2002. Preservation of equine sperm stores in the epididymis at $4^{\circ} \mathrm{C}$ for $24,28,72$ and 96 hours. Theriogenology 58, 401-404.

Januskauskas A, H Zilinskas. 2002. Bull semen evaluation post-thaw and relation of semen characteristics to bull's fertility. Vet Zootec 17, 1-8.

Jeyendran RS, HH Vanderven, M Perez-Pelaez, BG Crabo, LJD Zaneveld. 1984. Development of an assay to assess the functional integrity of the human sperm membrane and its relationship to other semen characteristics. J Reprod Fertil 47, 219-228.

Lambrechts H, F Van Niekerk, W Coetzer, S Cloete, HG Vander. 1999. The effect of cryopreservation on the survivability, viability and motility of epididymal African buffalo (Synceruscaffer) spermatozoa. Theriogenology 52, 1241-1249.

Lindemann CB, KS Kanous. 1989. Regulation of mammalian sperm motility. Arch Andrology 23, 1-22.

Martinez-Pastor F, V Garcia-Macias, M Alvarez, C Chamorro, P Herraez, P Paz, L Anel. 2006. Comparison of methods for obtaining spermatozoa from the cauda epididymis of Iberian red deer. Theriogenology 65, 471-485.

Martins CF, R Rumpf, DC Pereira, MN Dode. 2007. Cryopreservation of epididymal bovine spermatozoa from dead animals and its uses in vitro embryo production. Anim Reprod Sci 101, 326-331.

Martins CF, K Driessen, P Melo Costa, JO Carvalho-Neto, RV de Sousa, R Rumpf, MN Dode. 2009. Recovery, cryopreservation and fertilization potential of bovine spermatozoa obtained from epididymides stored at $5{ }^{\circ} \mathrm{C}$ by different periods of time. Anim Reprod Sci 116, 50-57.

Medeiros CMO, C Forell, ATD Oliveira, JL Rodrigues. 2002. Current status of sperm cryopreservation: why isn't it better? Theriogenology 57, 327-344.

Moore AI, EL Squires, JE Bruemmer, JK Graham. 2006. Effect of cooling rate and cryoprotectant on the cryosurvival of equine spermatozoa. J Equine Vet Sc 26, 215-218.

Parks JE, JK Grahan. 1992. Effects of cryopreservation procedures on sperm membranes. Theriogenology 8, 299-312.

Reyes-Moreno C, M Boilard, R Sullivan, M Sirar. 2002. Characterization and identification of epididymal factors that protect ejaculated bovine sperm during in vitro storage. Biol Reprod 66, 159-166.

Rodello L, HC Azevedo, SD Bicudo, MS Maia, DB Sousa, CC Sicherle. 2005. Comparação entre sistemas automatizado e geladeira/vapor de nitrogênio líquido na criopreservação de sêmen ovino. Resúmenes del Congresso Brasileiro de Reprodução Animal, Goiânia, Brasil.

Rodriguez-Martinez H. 2005. Methods for semen evaluation and their relationship to fertility. Resúmenes del Congresso Brasileiro de Reprodução Animal, Goiânia, Brasil.

Severo NC. 2009. Influência da qualidade do sêmen bovino congelado sobre a fertilidade. A Hora Veterinária 28, 167.

Siqueira JB, JD Guimarães, EP Costa, M Henry, CAA Torres, MVGB Silva. 2007. Relação da taxa de gestação com sêmen bovino congelado e testes de avaliação espermática in vivo. Rev Bras Zootec 36, 387-395.

Sostaric E, M Alberts, BM Gadella, TAE Stout. 2008. The roles of the epididymis and prostasomes in the attainment of fertilizing capacity by stallion sperm. Anim Reprod Sci 107, 237-248.

Terraciano PB, IC Bustamante-Filho, LV Miquelito, TR Arlas, FCRC Mattos, EP Passos, ER Oberst, EOC Lima. 2008. Criopreservação de espermatozóides eqüinos comparando duas curvas de congelamento combinadas com diluentes comerciais: uma análise laboratorial. Ciênc Rural 38, 1972-1977.

Tesarik J, C Mendoza, A Carreras. 1993. Fast acrosome reaction measure a highly sensitive method for evaluating stimulus-induced acrosome reaction. Fertil Steril 53, 424-430.

Thuwanut P, K Chatdarong, M Techakumphu, E Axner. 2008. The effect of antioxidants on motility, viability, acrosome integrity and DNA integrity of frozen-thawed epididymal cat spermatozoa. Theriogenology 70, 233-240.

Vasconcelos-Filho WF. 2010. Eficiência da congelação automatizada na viabilidade de sêmen bovino. 2010. Tesis máster, Instituto de Zootecnia, Universidade Federal Rural do Rio de Janeiro, Seropédica, Brasil. 